\title{
Corals' adaptive response to climate change
}

\section{Shifting to new algal symbionts may safeguard devastated reefs from extinction.}

T he long-term response of coral reefs to climate change depends on the ability of reef-building coral symbioses to adapt or acclimatize to warmer temperatures, but there has been no direct evidence that such a response can occur. Here we show that corals containing unusual algal symbionts that are thermally tolerant and commonly associated with high-temperature environments are much more abundant on reefs that have been severely affected by recent climate change. This adaptive shift in symbiont communities indicates that these devastated reefs could be more resistant to future thermal stress, resulting in significantly longer extinction times for surviving corals than had been previously assumed.

Reef-building scleractinian (stony) corals obligately host dinoflagellate algal symbionts (genus Symbiodinium), whose loss during mass coral-reef 'bleaching' as a result of increased seawater temperatures is a significant threat to coral reef ecosystems worldwide $^{1}$. Although acclimatization and/or adaptation of reef coral hosts and/or their algal symbionts are recognized as potentially mitigating the frequency and severity of these bleaching events ${ }^{1-3}$, no studies have been undertaken to test whether such responses actually occur on affected reefs.

The genus Symbiodinium is diverse, and many corals are relatively flexible in the type(s) of algal symbiont they contain, although one type is usually dominant in any given species and environment ${ }^{4-7}$. Because corals containing different symbionts can vary in their sensitivity to bleaching ${ }^{4,8}$ and can modify their symbiont communities in response to environmental change $e^{4,7,9,10}$, we investigated whether severe bleaching and mortality can select for stable host-symbiont combinations that are more thermally tolerant, raising the overall bleaching resistance of the reef as a result.

We undertook molecular surveys of Symbiodinium in shallow (less than $7 \mathrm{~m}$ depth) scleractinian corals from five locations in the Indo-Pacific that had been differently affected by the 1997-98 El Niño-Southern Oscillation (ENSO) bleaching event (Fig. 1; for sample details, see supplementary information). For these large-scale comparisons, restriction-fragment length polymorphisms in the symbionts' large-subunit ribosomal DNA were used to distinguish Symbiodinium in clades $\mathrm{A}, \mathrm{C}$ or $\mathrm{D}^{5,9}$.

In Panama, we surveyed ecologically dominant corals in the genus Pocillopora before, during and after ENSO bleaching. Colonies containing Symbiodinium in clade D were already common (43\%) in 1995 and

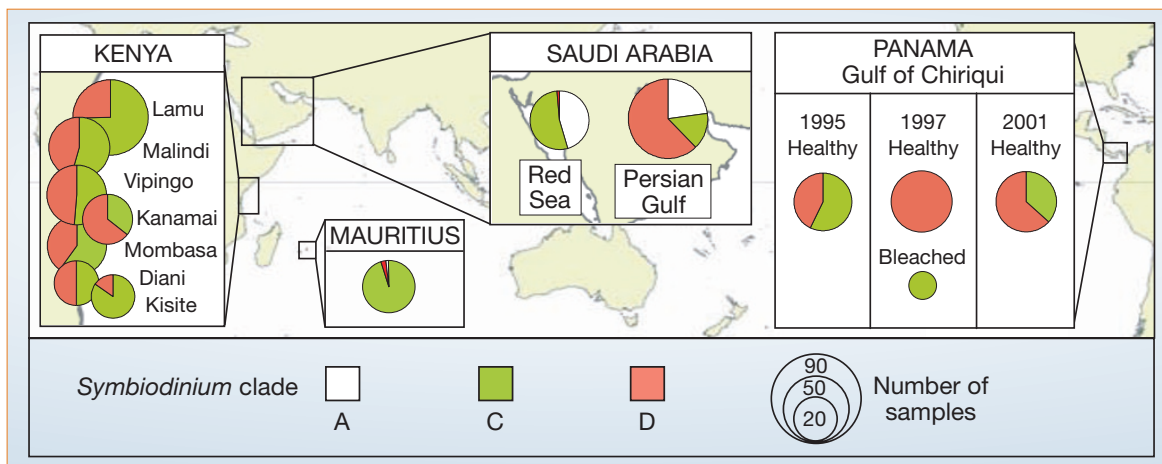

Figure 1 Distribution of Symbiodinium algae in shallow-water (less than $7 \mathrm{~m}$ depth) scleractinian corals from Kenya, Mauritius, Saudi Arabia and Pacific Panama. Pie charts show distribution of symbionts by site, except those for Panama, which show the distribution of symbionts at a single site before (1995: all colonies healthy), during (1997: some colonies healthy, others severely bleached) and after (2001: all colonies healthy) the 1997-98 El Niño. Size of pie charts is scaled to the square-root of sample size to reflect an equal area for each sample, as indicated by the inset scale. See supplementary information for sampling details for each country.

were unaffected by bleaching in 1997, while colonies containing clade $\mathrm{C}$ bleached severely $^{8}$. By 2001, colonies containing clade D had become dominant (63\%) on these reefs.

We also surveyed corals from the Persian (Arabian) Gulf that experience extremely high seasonal temperatures $\left(>33^{\circ} \mathrm{C}\right)$. Even these reefs were severely bleached in 1998 (ref. 11), when temperatures in some locations exceeded $38{ }^{\circ} \mathrm{C}$. We compared these with corals from the Red Sea that do not experience such seasonal temperature highs (typically $29^{\circ} \mathrm{C}$ ) and which were relatively unaffected in 1998 (ref. 11). We found that, in 2000-01, Gulf reefs were dominated by the same clade-D symbionts as were found in Panama (62\% of scleractinian colonies), whereas Red Sea reefs only rarely contained these symbionts ( $1.5 \%$ of colonies).

This comparison was repeated in the western Indian Ocean in 2000-02: corals from reefs in Kenya that were severely bleached by the combined effects of ENSO and the Indian Ocean Dipole in 1998 were compared with corals from Mauritius that had fortuitously escaped significant bleaching during the same event ${ }^{11}$. The findings were similar: in Kenya, 15-65\% of colonies contained clade $\mathrm{D}$, depending on site, compared with only $3 \%$ of colonies in Mauritius.

Taken together, these results indicate that corals containing thermally tolerant Symbiodinium in clade $\mathrm{D}$ are more abundant on reefs after episodes of severe bleaching and mortality, and that surviving coral symbioses on these reefs more closely resemble those found in high-temperature environments.

We have yet to determine the processes by which these symbiont shifts occur in coral populations (for example, there could be differential mortality of coral hosts and/or bleaching-induced symbiont change in individual colonies ${ }^{12}$ ). It is possible that affected reefs may revert to their original symbiont communities over time if they do not experience repeat warming episodes ${ }^{13}$. We also recognize that some corals (most notably the genus Porites) remain common on devastated reefs, even though they do not often contain clade-D symbionts. Nevertheless, we propose that the symbiont changes described here are a common feature of severe bleaching and mortality events, and predict that these adaptive shifts will increase the resistance of these recovering reefs to future bleaching.

Andrew C. Baker ${ }^{\star} \dagger$, Craig J. Starger $\neq$, Tim R. McClanahan ${ }^{\star}$, Peter W. Glynn\$

${ }^{*}$ Marine Program, Wildlife Conservation Society,

Bronx, New York 10460, USA

e-mail: abaker@wcs.org

$\dagger$ Center for Environmental Research and

Conservation and $\ddagger$ Department of Ecology,

Evolution and Environmental Biology, Columbia

University, New York, New York 10027, USA

$\$$ Rosenstiel School of Marine and Atmospheric

Science, University of Miami, Florida 33149, USA

1. Hughes, T. P. et al. Science 301, 929-933 (2003).

2. Coles, S. L. \& Brown, B. E. Adv. Mar. Biol. 46, 183-223 (2003).

3. Sheppard, C. R. C. Nature 425, 294-297 (2003).

4. Rowan, R., Knowlton, N., Baker, A. C. \& Jara, J. Nature 388, 265-269 (1997).

5. Baker, A. C. Annu. Rev. Ecol. Evol. Syst. 34, 661-689 (2003).

6. LaJeunesse, T. C. Mar. Biol. 141, 387-400 (2002).

7. Little, A. F., Van Oppen, M. J. H. \& Willis, B. L. Science 304, 1492-1494 (2004).

8. Glynn, P. W., Maté, J. L., Baker, A. C. \& Calderón, M. O. Bull. Mar. Sci. 69, 79-109 (2001).

9. Baker, A. C. Nature 411, 765-766 (2001).

10. Toller, W. W., Rowan, R. \& Knowlton, N. Biol. Bull. 201, 360-373 (2001).

11. Wilkinson, C. R. (ed.) Status of Coral Reefs of the World: 2002 (Australian Institute of Marine Science, Queensland, 2002).

12. Buddemeier, R. W. \& Fautin, D. G. Bioscience 43, 320-326 (1993)

13. Ware, J. R., Fautin, D. G. \& Buddemeier, R. W. Ecol. Model. 84, 199-214 (1996).

Supplementary information accompanies this communication on Nature's website.

Competing financial interests: declared none. 